\title{
Drought Tolerance in Several Tagetes L. Cultivars
}

\author{
Raluca CICEVAN ${ }^{1}$, Mohamad Al HASSAN ${ }^{2}$, Oscar VICENTE ${ }^{2 *}$, Monica BOSCAIU ${ }^{3)}$, Adriana SESTRAȘ ${ }^{1}$, \\ Radu SESTRAȘ ${ }^{1)}$ \\ ${ }^{1)}$ University of Agricultural Sciences and Veterinary Medicine Cluj-Napoca, Romania \\ ${ }^{2)}$ Institute of Plant Molecular and Cellular Biology (IBMCP, UPV-CSIC) \\ 3) Instituto Agroforestal Mediterráneo (IAM, UPV), Universitat Politècnica de València, Valencia, Spain \\ ${ }^{*}$ Corresponding author, e-mail: ovicente@ibmcp.upv.es
}

Bulletin UASVM Horticulture 71(2) / 2014

Print ISSN 1843-5254, Electronic ISSN 1843-5394

DOI:10.15835/buasvmcn-hort:10553

\begin{abstract}
Drought is the most important single environmental stress factor that reduces crop yields worldwide. In the context of global climate change, selection and/or development of drought-resistant varieties of cultivated plants is becoming an urgent need for agriculture in arid and semiarid regions. In this work we have analysed physiological (growth inhibition) and biochemical (proline levels) responses to water stress of 5 cultivars of Tagetes patula and 5 cultivars of T. tenuifolia. The most drought-tolerant cultivars were found to be 'Bolero' in $T$. patula and 'Luna gold' in T. tenuifolia, while 'Orion' and 'Luna orange' were the most sensitive for each species.
\end{abstract}

Keywords: Tagetes patula, Tagetes tenuifolia, drought, abiotic stresses, proline.

Introduction Among all the abiotic stress factors affecting agricultural production, drought causes the most drastic reduction in crops yield worldwide. On the background of global warming, with increasing scarcity of water resources for irrigation, studies on the responses to drought of cultivated plants and selection of relatively resistant varieties are becoming extremely important. In addition, effective approaches to increase stress tolerance of plants using modern biotechnological tools require a deep knowledge of the intricate physiological, biochemical and molecular networks underlying plant stress tolerance mechanisms. One of the most general responses to abiotic stress is based on the biosynthesis and accumulation of specific osmolytes for cellular osmotic adjustment and, for many species, proline (Pro) content is considered as a reliable marker of the level of stress affecting the plants. The present work focuses on plants of the Tagetes genus, which are among the most well-known ornamentals, but are also valuable medicinal plants and are used as well in the food and cosmetics industries (Sehrish et al. 2013)

Aims The main objectives of the work were to measure the degree of growth inhibition of
5 cultivars of Tagetes patula L. and 5 cultivars of $T$. tenuifolia Cav. subjected to water stress treatments, to establish their relative tolerance to drought and the possible correlation with proline contents in plants of the different cultivars.

Materials and Methods Seeds of five commercial cultivars of each species were sown in pots on a mixture of peat and vermiculite and watered with Hoogland's nutritive solution for three weeks; then watering was completely stopped for the plants subjected to the drought treatment and continued for control plants. After three-week treatments, plants were sampled and weighed on a precision balance (fresh weight, FW); a portion of each sample was dried in an oven for several days to determine the dry weight (DW). Pro was quantified by the classic method of Bates (1973), with slight modifications (Vicente et al. 2004).

Results Differences in drought tolerance were detected between the two species investigated (average inhibition of growth was relatively higher in T. patula), and among cultivars within each species. 'Bolero', in T. patula, and 'Luna gold', in T. tenuifolia, appear to be more tolerant than the other four studied cultivars of each species, showing a smaller reduction of fresh weight after 
Tab. 1. Inhibition of growth under water stress (WS) conditions

(3 weeks without irrigation) in Tagetes patula and T. tenuifolia cultivars

\begin{tabular}{|c|c|c|c|c|c|c|c|}
\hline \multirow{2}{*}{ Species } & \multirow{2}{*}{ Cultivar } & \multicolumn{2}{|c|}{ FW (g) FW ( $\%$ of control $)$} & \multirow{2}{*}{ Species } & \multirow{2}{*}{ Cultivar } & \multicolumn{2}{|c|}{ FW (g) FW ( $\%$ of control $)$} \\
\hline & & Control & WS & & & Control & WS \\
\hline T. patula & Szinkeverek & 8.68 & 17.28 & T. tenuifolia & Sarga & 11.25 & 12.88 \\
\hline T. patula & Orion & 8.78 & 13.32 & T. tenuifolia & Luna gold & 9.08 & 57.71 \\
\hline T. patula & Bolero & 6.53 & 25.75 & T. tenuifolia & Luna rot & 6.03 & 37.69 \\
\hline T. patula & Robuszta & 5.18 & 18.11 & T. tenuifolia & Luna lemon & 5.47 & 9.24 \\
\hline T. patula & Orange flame & 6.19 & 22.29 & T. tenuifolia & Luna orange & 7.16 & 5.19 \\
\hline
\end{tabular}

Tab. 2. Proline accumulation after water stress (WS) treatments

in Tagetes patula and T. tenuifolia cultivars

\begin{tabular}{lccccccc}
\hline Species & Cultivar & $\begin{array}{c}\text { Pro }(\mu \mathrm{mol} / \mathrm{g} \\
\mathrm{DW}) \\
\text { Control }\end{array}$ & $\begin{array}{c}\text { Pro (fold- } \\
\text { increase over } \\
\text { control) } \\
\text { WS }\end{array}$ & Species & Cultivar & $\begin{array}{c}\text { Pro }(\mu \mathrm{mol} / \mathrm{g} \\
\mathrm{DW})\end{array}$ & $\begin{array}{c}\text { Pro (fold- } \\
\text { increase } \\
\text { Control } \\
\text { Control) } \\
\text { Cons }\end{array}$ \\
\hline T. patula & Szinkeverek & 6.17 & 58.84 & T. tenuifolia & Sarga & 8.36 & 10.53 \\
\hline T. patula & Orion & 3.88 & 67.35 & T. tenuifolia & Luna gold & 15.61 & 2.89 \\
\hline T. patula & Bolero & 6.85 & 9.81 & T. tenuifolia & Luna rot & 8.71 & 30.26 \\
\hline T. patula & Robuszta & 4.48 & 61.53 & T. tenuifolia & Luna lemon & 7.23 & 31.91 \\
\hline T. patula & Orange & 5.31 & 47.11 & T. tenuifolia & Luna orange & 6.21 & 39.34 \\
\hline
\end{tabular}

three weeks without irrigation, as compared to the non-stresses controls; conversely, 'Orion' and 'Luna orange' seem to be the most droughtsensitive cultivars for each species, as they show the largest degree of growth inhibition (Table 1)

Pro contents in the plants increased in all cases in response to drought treatments, but with large differences among cultivars, from $\sim 3$-fold in 'Luna gold' to almost 70-fold in 'Orion'. For each species, and considering all cultivars, a good qualitative correlation was observed between the relative increase in Pro levels and the sensitivity to water stress. Thus, the most tolerant cultivars ('Bolero' and 'Luna gold') accumulated less Pro, indicating that they were indeed less stressed than other cultivars under the same experimental conditions.

Conclusion All investigated T. patula and T. tenuifolia cultivars were negatively affected by water stress, but showing widely variable levels of growth inhibition; it is therefore possible to select specific cultivars with significantly higher drought tolerance. The good correlation between relatively higher resistance to water stress with lower accumulation of Pro confirms this osmolyte as a reliable stress marker in Tagetes species.

ACKNOWLEDGEMENTS: This paper was published under the frame of European Social Fund, Human Resources Development Operational Programme 2007-2013, project no. POSDRU/159/1.5/S/132765.

\section{REFERENCES}

1. Sehrish SS, Khalid R, Qureshi B, Ali Ahsan (2013). Tagetes minuta L., a useful underutilized plant of family Asteraceae. Pak. J. Weed. Sci. Res. 19(2):179-189.

2. Bates LS, Waldren RP and Teare ID (1973). Rapid determination of free proline for water stress studies. Plant Soil 39, 205-207.

3. Vicente O, Boscaiu M, Naranjo MA, Estrelles E, Belles JM and Soriano P., 2004. Responses to salt stress in the halophyte Plantago crassifolia (Plantaginaceae). J. Arid Environ. 58: 463-481. 